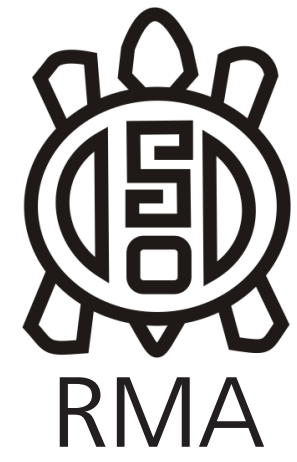

Antropología Social

\title{
Huellas y sustratos. El problema de las lenguas indígenas en el relato antropológico argentino entre 1930 y 1950
}

\author{
Traces and substrates. The issue of indigenous languages in Argentinian \\ anthropological narratives between 1930 and 1950
}

*Luisa Domínguez

Universidad de Buenos Aires / Consejo Nacional de Investigaciones Científicas y Técnicas, Argentina. E-mail: domingluisa@gmail.com

\begin{abstract}
Resumen
Durante la primera mitad del siglo XX, es posible reconocer en distintos discursos referidos a la historia argentina una tendencia generalizada a ubicar a los pueblos indígenas en el pasado natural del país. Sin embargo, encontramos en esta tendencia ciertos matices que son el objeto de este artículo. Partimos de la idea de que entre la denominada "década infame" y la emergencia del peronismo se asiste a una reorganización de la esquematización temporal de las ciencias, reorganización que impactará en el tratamiento del tema indígena. El artículo se detiene, específicamente, en el abordaje del problema de las lenguas indígenas durante el periodo comprendido entre 1930 y 1950 en distintos espacios disciplinares (historia, ciencias antropológicas y folklore), cuyas definiciones epistemológicas determinaron, según intentaremos demostrar, una segmentación temporal particular. Para ello, analizamos una serie de documentos que abarca algunas producciones de José Imbelloni, Félix Faustino Outes y Juan Alfonso Carrizo, así como también algunos programas de gestión institucional de centros académicos porteños.
\end{abstract}

Palabras clave: Pueblos indígenas, Lenguas indígenas, Historia, Ciencias antropológicas, Folklore.

\begin{abstract}
During the first half of the twentieth century, it is possible to identify different discourses that, referring to the national history of Argentina, present a generalized tendency of situating indigenous peoples within the natural past of the country. However, we find in that tendency certain distinguishing characteristics that are our object of study in this paper. We start from the idea that between the so-called "infamous decade" and the emergence of Peronism there is a reorganization of the temporal schematization of the sciences in Argentina, something that will affect the treatment of indigenous issues. This article focuses specifically on the theoretical approach to the problem area of indigenous languages that takes place between 1930 and 1950, and through different disciplinary areas (history, anthropological sciences and folklore). We demonstrate how these disciplines, through specific epistemological definitions, determine a particular temporal segmentation. To that end, we analyze a series of documents that includes productions by José Imbelloni, Félix Faustino Outes and Juan Alfonso Carrizo, together with institutional management documentation from academic centers in Buenos Aires.
\end{abstract}

Key words: Indigenous peoples, Indigenous languages, History, Anthropological sciences, Folklore

Durante la primera mitad del siglo $X X$, una vez consolidado el Estado nacional argentino, tuvo lugar una paulatina (aunque, al mismo tiempo debemos decir, relativa) autonomización de los campos político y científico. En este proceso, la problemática indígena se convirtió en un asunto mayormente abordado por la ciencia y los encargados de su estudio fueron especialistas provenientes de distintas disciplinas. Tal como sostiene Raúl Mandrini (2003), los análisis sobre la cuestión indígena producidos en los centros académicos de Buenos Aires estuvieron a cargo de especialistas en antropología y folklore, mientras que los historiadores (y otros intelectuales a cargo de la definición y estudio de la cultura nacional, agregamos nosotros) desestimaron su abordaje. Esta distribución epistemológica supuso tematizaciones y localizaciones temporales particulares de estos pueblos en el relato histórico y científico: en algunas ocasiones se los inscribió en el ámbito de la 
historia natural del territorio nacional, mientras que otras (pocas) veces se los asoció con el pasado reciente o como parte de las características de la "argentinidad" (García Fanlo, 2011). Estas variaciones serán el objeto de este trabajo, cuyo principal propósito es analizar las distintas tematizaciones y asignaciones temporales de los pueblos indígenas en el discurso científico en función de ciertas coyunturas políticas particulares. Para ello, prestaremos especial atención al problema de las lenguas indígenas como uno de los temas centrales en los que emerge esta problemática.

Según intentaremos demostrar, si bien durante el periodo propuesto (1930-1950) es posible identificar un borramiento de estos grupos de la contemporaneidad y una consecuente ubicación en los tiempos "prehistóricos" dentro del discurso de la historia, esta tendencia fue tiñéndose de distintos matices. Así, sostenemos que junto con la institucionalización del folklore entre mediados de la década del treinta e inicios del cuarenta (Chein, 2006) se retomaron discusiones sobre el lugar que se les asignaría a los pueblos indígenas en la construcción del patrimonio nacional; discusiones que se profundizan con la emergencia del peronismo. Partimos de la idea de que la ubicación del pasado indígena en determinados segmentos temporales no solo encuentra su explicación en la ya mencionada distribución epistemológica, es decir, en las delimitaciones y definiciones disciplinares y metodológicas; sino que también ha sido efecto, como puede suponerse a priori, de coyunturas específicas en que se trató el problema de la identidad nacional con especial atención.

En primer lugar, reconstruiremos el lugar asignado a la cuestión indígena en la década del treinta a partir del análisis de algunos acontecimientos clave para el desarrollo del conocimiento antropológico de la Argentina: por un lado, la publicación del primer tomo de la Historia de la Nación Argentina (Levene, 1936), a cargo de la gran mayoría de los especialistas del campo en el periodo. Particularmente nos detendremos en la sección a cargo de José Imbelloni, "Las lenguas indígenas del territorio argentino". Abordaremos, en segundo lugar, las gestiones de Félix Faustino Outes frente a dos de las más relevantes instituciones en el ámbito disciplinar mencionado: el Museo Etnográfico dependiente de la Facultad de Filosofía y Letras de la Universidad de Buenos Aires y la Sociedad Argentina de Antropología. La parte central del artículo consiste en la reconstrucción de una instancia de reconfiguración del campo antropológico a partir del proceso de institucionalización del folklore y el valor que adquieren las lenguas indígenas y el arte verbal en este ámbito. Para ello, abordaremos algunos aspectos de la obra de Juan Alfonso Carrizo y la publicación de Concepto y praxis del folklore como ciencia, de Imbelloni. Finalmente, revisaremos el devenir de este proceso en el marco del peronismo.

\section{Huellas "arqueológicas" en la historia}

Durante los años treinta se dieron importantes transformaciones en el país debido a la crisis económica mundial de 1929, situación que trajo consigo el pasaje de una Argentina agroexportadora a un modelo volcado hacia el interior. A su vez, en estos años se modernizaron las principales ciudades, aumentaron las migraciones internas hacia los centros urbanos y cesó provisoriamente la inmigración externa (Cattaruzza, 2001, 2016). Uno de los efectos de esta nueva configuración del país fue que se retomaron las disputas por la definición de la "identidad nacional" (Escudero, 2010). Independientemente de los matices, es posible hallar un consenso acerca de que el centro de la nacionalidad argentina se encontraba, entonces, en las "formas culturales antiguas, telúricas, que se suponían propias del interior rural" (Cattaruzza, 2007, p. 152).

En este clima se produjeron significativas transformaciones en el campo historiográfico al tiempo que se consolidaba una línea profesional de historiadores asociados con la Nueva Escuela Histórica, que contó entre sus representantes con Ricardo Levene, Emilio Ravignani y Rómulo Carbia. Por estos años, ellos lograron ocupar posiciones centrales en las principales universidades del país, además de formar parte de la ya clásica Junta de Historia y Numismática Americana (actual Academia Nacional de Historia). Este grupo, a su vez, se encontraba estrechamente asociado con el poder político, razón que explica el encargo de escribir la "historia oficial". En estas condiciones es que tiene lugar la publicación, en 1936, del primer tomo de los catorce volúmenes de la Historia de la Nación Argentina (HNA en adelante), dirigida por el presidente de la Junta, Levene.

Se trata de una obra monumental con la que sus gestores buscaron abordar la historia nacional desde los tiempos "prehistóricos" hasta "su constitución definitiva, en 1862", según proclama su subtítulo. El plan consistía en la construcción de un relato que se iniciaba en las etapas "pre y protohistóricas" con el objetivo de reconstruir "el proceso genético de la sociedad argentina desde sus orígenes" (Levene, 1936, p. XXVI). La periodización finalizaba en 1862, año con que el que sus impulsores marcaban la consolidación del Estado argentino. A su vez, el proyecto partía de la idea de que los estudios históricos se encontraban en un estado de "florecimiento"; por lo que su organizador proponía "comenzar el inventario y valorización de lo mucho que se ha hecho, realizando una obra de síntesis histórica" (Levene, 1936, p. XXV).

El primero de los volúmenes, atinente al periodo pre y protohistórico, fue escrito por reconocidos especialistas en ciencias antropológicas, tales como Milcíades Alejo Vignati, Eduardo Casanova, Enrique Palavecino, Fernando Márquez Miranda, Francisco de Aparicio, Antonio Serrano y José Imbelloni, muchos de los cuales fueron miembros fundadores de la Sociedad Argentina de Antropología 
(SAA en adelante), acontecimiento que también tuvo lugar en 1936. Este primer volumen cuenta con dos secciones: la primera, titulada "El hombre prehistórico", y la segunda, "Los aborígenes prehispánicos e históricos". Esta última sección cuenta con una introducción seguida de los capítulos correspondientes a los grupos indígenas de las distintas regiones del territorio nacional: Noroeste, Chaco, Río de La Plata, La Pampa y Patagonia.

Dicha introducción, a cargo de Imbelloni, ${ }^{1}$ se titula "Lenguas indígenas del territorio argentino". En primer lugar, el autor realiza una breve historización de los estudios en materia de lingüística indígena, lo que abona el plan de escritura de la obra, con la que se pretendía dar cuenta del estado de desarrollo de la ciencia en la Argentina. Luego, introduce una clasificación de las lenguas indígenas en función de los grupos raciales:

En cuanto a los idiomas, las áreas lingüísticas se han mostrado en América suficientemente adherentes a la división racial y cultural, de tal manera que, prácticamente, la división lingüística en grupos y familias es usada aún en nuestros días como subsidiaria de aquéllas. (Imbelloni, 1936 b, p. 183)

Este fragmento justifica el hecho de que la introducción de toda la sección se refiera, precisamente, a las lenguas indígenas, debido al valor que por entonces tenía el criterio lingüístico para la sistematización y diferenciación de los grupos indígenas del país.

A la clasificación de los grupos raciales, le sigue una tabla que contiene un listado de las lenguas indígenas del territorio nacional. El trabajo continúa con una breve descripción de cada una de las lenguas. En la tabla mencionada, el autor distingue con una cruz las lenguas consideradas extintas, lo que implica, por oposición, el reconocimiento de otro grupo de lenguas indígenas con vigencia comunicativa en el momento en que se escribe la obra. Tal contraste pone en evidencia un supuesto del periodo que pretendía inscribir la existencia de los pueblos indígenas en los tiempos pre y protohistóricos (Podgorny, 2001, 2002), operación discursiva que facilitaba su borramiento del plano contemporáneo. Es decir, si bien Imbelloni admite que algunas lenguas (la gran mayoría, de hecho) se encontraban en uso en ese momento (lo que implicaba, a su vez, reconocer la existencia de diversos grupos indígenas), su planteo incurre en una extendida

\footnotetext{
1 José Imbelloni (1885-1967) fue un antropólogo de origen italiano que se radicó definitivamente en la Argentina en la década del veinte. En 1936, logró ubicarse en una posición estratégica dentro del campo científico: participó en la Historia de la Nación Argentina con dos artículos (1936a y b), fue miembro de la comisión fundadora de la SAA y publicó, ese mismo año, Epítome de culturología (1936c), una obra en la que expone los principales lineamientos de la escuela históricocultural a la que adscribía, adaptándolos a temáticas de estudio del ámbito local. Un año más tarde, fue designado profesor titular de Antropología y Etnología General en la Facultad de Filosofía y Letras de la Universidad de Buenos Aires, ámbito desde donde ejercerá una continuada y decisiva actividad en la disciplina.
}

tendencia característica de toda la primera mitad del siglo XX que consiste en distinguir y organizar la historia argentina en dos grandes segmentos aparentemente sucesivos, a pesar de su simultaneidad empírica: el primero, correspondiente a los pueblos indígenas; el segundo, al mundo criollo.

La idea de ubicar a los pueblos indígenas en el pasado prehistórico es deudora de la tradición decimonónica que estableció una distribución temática entre la antropología, la arqueología, la historia y la sociología en función de la distancia temporal y espacial entre el objeto y la posición del investigador. ${ }^{2}$ Esta esquematización de la ciencia favoreció y permitió justificar, por lo menos en el ámbito local, los mecanismos de invisibilización de los grupos indígenas y el silenciamiento de sus lenguas. La emergencia de esta perspectiva puede rastrearse hacia fines del siglo XIX, en la tradición ameghiniana de estudios antropológicos, centrada en el análisis del "hombre fósil" de la región pampeana. Sin embargo, Fígoli (2004) señala que existió también una tradición opuesta, la "transformista", que buscaba el contacto con las culturas indígenas contemporáneas, también denominada "humanista". ${ }^{3}$ De cualquier manera, en los dos casos se partía de ciertas ideas en común: por un lado, la desaparición inminente de los pueblos indígenas, supuesto que marcó las ciencias antropológicas y disciplinas afines durante gran parte del siglo XX; por el otro, la construcción de un pasado heroico de los pueblos indígenas y un presente de profunda degradación.

En las ciencias antropológicas estos supuestos se mantienen por lo menos durante las primeras cuatro décadas del siglo XX. Esto puede verse en el programa de gestión de Félix Outes ${ }^{4}$ frente al Museo Etnográfico de la Universidad de Buenos Aires, una de las instituciones más importantes dedicadas al estudio y exposición de distintas temáticas asociadas con este ámbito del conocimiento. Durante la dirección de Outes entre 1930 y 1936, se revela una preferencia por la investigación de gabinete o la exploración de yacimientos arqueológicos, mientras que no se registra (más allá de ser uno de los propósitos de su

\footnotetext{
2 Esquemáticamente, esta distribución sería la siguiente, según la relación del investigador con el objeto: historia (+distancia temporal, -distancia espacial), sociología (-distancia temporal, -distancia espacial), antropología (-distancia temporal, +distancia espacial), arqueología (+distancia temporal, +distancia espacial) (Boivin, Rosato y Arribas, 2016). Otra reflexión sobre el tema se encuentra en Piazzini Suárez (2006).

${ }^{3}$ Fígoli (2004) plantea que la tradición ameghiniana buscaba reponer cronologías que "no admitían saltos, ni catástrofes, todo era sucesión gradual y sin interrupción, fueran seres vivos o culturas" (p. 73). La tradición transformista, cuyos principales representantes fueron Francisco Moreno y Carlos Burmeister, se proponía, en cambio, la clasificación racial, sin tener en cuenta los saltos temporales o los "eslabones perdidos".

${ }^{4}$ Félix Faustino Outes (1878-1939) fue bibliotecario de oficio, docente universitario e investigador. A lo largo de su carrera se interesó por la historia, arqueología, geografía y lingüística, principalmente, y ocupó una posición de relevancia en el ámbito académico argentino al ser designado en importantes cargos para las ciencias antropológicas.
} 
gestión) el trabajo etnográfico. (Esta tendencia también puede identificarse en el tipo de aporte que realizó Outes al estudio de las lenguas indígenas, consistente en la edición, comentario y puesta en circulación de materiales lingüísticos compilados por otros agentes, como misioneros y viajeros [Domínguez, 2018].) En el plan de reorganización del Museo que él propone, plantea como sus principales objetivos los siguientes:

El Museo se interesará en estudiar, particularmente, los caracteres somatológicos de los naturales del noroeste argentino; en determinar los rasgos esenciales de las culturas marginales, prehispánicas, de nuestro gran río histórico (Paraná); en reunir, tratando de fijar su posición estratigráfica, los restos industriales y, quizá, los del hombre mismo, que ofrecen los "conchales" litorales hasta la fuegia; y en acumular, cuanto antes, en forma rigurosamente sistemática, las manifestaciones culturales de los indígenas que aun subsisten en las gobernaciones del Chaco y Formosa. (Outes, 1931, p. 36)

La última parte de este fragmento revela una tensión entre estudios del pasado y de la actualidad. Con todo, si bien hay una referencia a los pueblos "aun subsistentes" de la región del Gran Chaco, espacio etnográfico preferencial para la antropología del periodo (Gordillo, 2006), en el resto de los documentos ligados a su gestión no identificamos ninguna propuesta de emprender expediciones para el relevamiento etnográfico (situación que puede deberse, sin embargo, al profundo desfinanciamiento que atravesó el Museo durante los años en que Outes fuera su director).

En ese mismo texto, por otra parte, sugiere la organización de cuatro departamentos en la institución: antropogeografía, antropología física, etnografía y folklore. Respecto de estos dos últimos, les asigna el estudio de "la acción que haya ejercido el ambiente en las unidades culturales argentinas; las influencias periféricas o extracontinentales a que pudieron estar sometidas en diversas épocas, su grado de penetración, como los rastros que han dejado en cada complejo" (Outes, 1931, p. 38). En este caso, "folklore" pareciera ser una simple etiqueta, ya que la propuesta es, fundamentalmente, etnológica. Además, la superposición de los objetos de ambas disciplinas permite reconocer una etapa en la que aún no había definiciones fijas y claramente delimitadas de cada área, sino que los estudios folklóricos aún se encontraban subordinados a los antropológicos. En definitiva, con la creación de este departamento el director se proponía continuar con una de las preocupaciones centrales de la antropología del periodo: la organización tipológica de las distintas culturas y la identificación de rutas de migración. Al mismo tiempo, planteaba el abordaje de las características y relaciones interculturales históricas $y$, si bien al final de la cita menciona el estudio de los rastros dejados en cada complejo, el uso permanente del tiempo pretérito pone en evidencia una concepción de las culturas indígenas como huellas del pasado en el presente y no como una realidad contemporánea.

Por su parte, la SAA, también presidida por Outes (el único miembro que no participó de la $H N A$ ), fue creada con el objetivo de proveer un espacio que "coordinara los esfuerzos de los especialistas y estableciera lazos de cordialidad entre ellos" y que "intensificara los estudios antropológicos en el país" (Outes, 1937, p. 202). En consonancia con los casos expuestos anteriormente, esta sociedad se abocó, principalmente, a la investigación arqueológica, impronta que mantiene hasta la actualidad (Podestá, 2007). Desde sus inicios, tuvo como programa de investigación predilecto la búsqueda de materiales arqueológicos que permitieran reconstruir el pasado de los pueblos indígenas, mientras que no se registran trabajos etnográficos que los consideren en su presente. Esto queda en evidencia en los sucesivos números de su revista, Relaciones.

Tanto la organización del primer tomo de la HNA como las dos gestiones de Outes mencionadas anteriormente son sintomáticas de una práctica habitual en la antropología de la época, que Georges Balandier (1970, p. 15) ha denominado "huida de lo actual". En este mismo sentido, Axel Lazzari (2004) coincide en que los antropólogos en la Argentina de principios y mediados del siglo XX no se encontraban preocupados por los "problemas de su tiempo"; antes bien,

[...] ser antropólogo (o etnólogo, según otras definiciones) significaba constituirse como especialista en una o varias de las siguientes áreas: la raciología de las poblaciones fósiles, el pasado aborigen prehispánico ("antigüedades") y, en muchísima menor medida, el "salvamento" de las culturas indígenas que habian sobrevivido a las campañas de Pampa-Patagonia y Chaco. (Lazzari, 2004, p. 206)

Como explicamos, la cuestión indígena fue una temática mayormente abordada por los especialistas en ciencias antropológicas, que ubicaban su objeto de estudio en un pasado aún más lejano que los historiadores. Metodológicamente, durante este período los análisis partían de datos extraídos de fuentes etnohistóricas principalmente $y$, en menor medida, de exploraciones arqueológicas, tal como plantea Gastón Julián Gil (2016). Las investigaciones de campo, por su parte, fueron significativamente más escasas que en épocas anteriores (tal es el caso de los registros antropológicos y lingüísticos de Juan Bautista Ambrosetti o de Roberto Lehmann-Nitsche entre fines del siglo XIX e inicios del XX). ${ }^{5}$ Posteriormente, en la década del cuarenta, esta distribución temporal se revertirá parcialmente,

\footnotetext{
${ }^{5}$ Sin embargo, hubo algunas excepciones, como es el caso de Alfred Metraux o Enrique Palavecino, quienes desde Tucumán realizaron importantes etnografías entre hacia fines de la década del veinte e inicios de la del treinta (véase Carrizo, 2010; Montani, 2016; Perilli de Colombres Garmendia, 2006).
} 
según intentaremos demostrar, con la proliferación de estudios de folklore y con algunos acontecimientos de la vida política que dieron mayor visibilidad a los grupos indígenas.

\section{"Sustrato" folklórico}

Si bien en la década del cuarenta se fundan las instituciones más importantes dedicadas a la investigación folklórica, hubo en las dos décadas anteriores algunos antecedentes que debemos mencionar. Así, en el año 1921 se realiza la primera Encuesta Nacional de Folklore impulsada por el Consejo Nacional de Educación, cuyo resultado sirvió de base para la creación del Instituto de Literatura Argentina de la Universidad de Buenos Aires. Diez años después, en 1931, Carlos Vega (cercano a la figura de Imbelloni y, posteriormente, también simpatizante del peronismo) funda el Gabinete de Musicología Indígena en el Museo Argentino de Ciencias Naturales, una de las instituciones precursoras en el país dedicadas al estudio de las manifestaciones musicales del folklore, que metodológicamente combinó etnografías indígenas, mestizas y criollas (Vega, 2016 [1946], p. 7). Por su parte, en 1936, Berta Vidal de Battini comenzó a realizar encuestas sobre variedades de habla regionales del país y a compilar material folklórico en distintas provincias, tarea que se extendió por treinta años (véase Blache y Dupey, 2007). Mientras que en 1937, se crea el Instituto de Historia, Lingüística y Folklore en la naciente Facultad de Filosofía de la Universidad de Tucumán, dirigido por Manuel Lizondo Borda (Blache y Dupey, 2007).

Sin embargo, como ya se dijo, fue a inicios de la década del cuarenta cuando tuvieron lugar ciertos acontecimientos clave que remiten a un proceso de institucionalización del folklore y a la problematización de las definiciones y sus límites disciplinares (Blache, 1991-1992, p. 80). La Argentina de entonces venía de una fuerte crisis política y económica, marcada por el fraude electoral y por un profundo empobrecimiento de los pequeños productores agrarios. Esta pobreza había supuesto la migración de zonas rurales a los centros urbanos, creándose las primeras villas miserias. En 1943, en un contexto mundial signado por la Segunda Guerra Mundial y por el temor al avance del comunismo, tuvo lugar a un nuevo golpe militar con el que sus impulsores buscaron desarrollar y modernizar la economía nacional a través de la industrialización del país, lo que supuso una reconfiguración de social de las grandes ciudades. En estas condiciones, además, la figura de Juan Domingo Perón comienza a cobrar gran visibilidad entre las clases populares, gracias a las favorables medidas que implementó en calidad de director del Departamento Nacional del Trabajo (luego denominado Secretaría de Trabajo y Previsión) (Cattaruzza, 2016).

En esta coyuntura, imperaba la idea de que la Argentina se encontraba atravesando por un momento poblacional crítico que se explicaba a partir de la baja natalidad, la ausencia de inmigración y la "degeneración" racial debido al mestizaje (véase Lazzari, 2002; Villalón, 2012). ${ }^{6}$ Este diagnóstico resultó en una considerable proliferación de estudios folklóricos, cuyo objeto se demarcaba en función de un criterio fundamentalmente clasista. Es decir, estos estudios prestaban especial atención al sedimento inerte de una cultura otrora hegemónica, depositado en las manifestaciones culturales de los campesinos empobrecidos y de los grupos más carenciados de las urbes, tal como explica Martha Blache (1991-1992, p. 80-81). Esta nueva etapa del folklore se distinguió de la del primer cuarto de siglo, cuando las problemáticas abordadas se inscribían en el "pensamiento nacionalista" con el que se buscaba construir e instalar una identidad nacional que contuviera y homogeneizara la diversidad poblacional correspondiente a los procesos inmigratorios de fines del siglo XIX e inicios del XX (Fígoli, 2004; De Jong, 2005).

Algunos de los acontecimientos que dan lugar a esta nueva etapa del folklore son la fundación del Instituto Nacional de la Tradición y la publicación de Concepto y praxis del folklore como ciencia de Imbelloni, que analizaremos a continuación.

El Instituto Nacional de la Tradición fue creado en 1943 por el Poder Ejecutivo Nacional. Su primer director fue el catamarqueño Juan Alfonso Carrizo, quien desde la década del veinte venía incursionando en el ámbito del folklore, registrando particularidades propias del Norte argentino. En la primera publicación del Instituto, que se puso en circulación pocos años después de su fundación, Carrizo plantea como el principal objeto de interés para el estudio del folklore lo que hoy conocemos como "arte verbal", perteneciente al "folklore espiritual" del pueblo. La definición que plantea es la siguiente:

Así, aunque el Folklore abarca todo el patrimonio cultural subyacente en la sociedad civilizada, es propósito de la Revista ocuparse con especialidad en el estudio del llamado folklore espiritual, por ser el que se está perdiendo con mayor rapidez y a ojos vistas. Cada viejo que muere es una página desprendida del libro de nuestras tradiciones, y cada generación se lleva a la tumba un poco del alma nacional, que nada ni nadie podrá sustituir, pues ninguna pieza de folklore material, por artística que sea, ni aún un museo lleno de espuelas, de estribos, de trenzados, etc., tendrán el valor representativo de un canto o una poesía. (Carrizo, 1948, p. 8. Subrayado en el original)

\footnotetext{
${ }^{6}$ En 1940, el Museo Social Argentino organiza el Congreso de la Población, al que asisten tanto políticos como especialistas en distintas áreas. El objetivo de este evento era ofrecer soluciones frente a la situación poblacional del país. Tal como establece Lazzari (2002), en el Congreso participaron tres especialistas miembros de la Sociedad Argentina de Antropología, quienes no emitieron opinión, según se registra en la sesión plenaria. El autor asocia esta actitud con las principales temáticas abordadas por la antropología por entonces-como explicamos más arriba- que escapaban a problemas contemporáneos. A esto se le sumaba el hecho de que, en consonancia con la opinión general, para los antropólogos "los indígenas vivos eran una cuestión 'inactual'" (Lazzari, 2004, p. 207).
} 
De hecho, fue este tipo de material en particular lo que principalmente recolectó en sus viajes de exploración por varias provincias de Cuyo y el Noroeste argentino a lo largo de la década del veinte. Desde los inicios de su proyecto, Carrizo sostuvo que la poesía folklórica de esta región seguía el modelo de la literatura del Siglo de Oro español y que tenía una fuerte impronta de la tradición cristiana (Chamosa, 2012), idea que mantuvo a lo largo de toda su obra. En 1945, publica Antecedentes hispanomedioevales de la poesía tradicional argentina, que planta, desde un primer momento, lo siguiente:

Si desechamos por inconsistente la pretendida influencia de la cultura indo-americana en nuestro acervo poético tradicional, desde que el quichua, idioma en que están los cantares recogidos en la lengua indígena del Tucumán, por ejemplo, no se habló en nuestro país antes de la venida de los españoles, tenemos necesariamente que llevar los ojos al patrimonio espiritual del pueblo español de la Conquista y Colonización si queremos conocer el nuestro. (Carrizo, 1945, p. 19)

En este fragmento, aun reconociendo la narrativa en lengua indígena, Carrizo desestima su pureza o su posibilidad de ser considerada un rasgo constitutivo del patrimonio nacional, por tratarse de un fenómeno que llegó a esa región después de la Conquista. Con esta operación, el autor suprime el sustrato indígena del folklore argentino, ya que, en el caso de aparecer algunos elementos en el material recogido, se los atribuye a una influencia posthispánica.

Bentivegna (2012) da cuenta del contraste de esta hipótesis con la de Ricardo Rojas, con quien en la década del veinte Carrizo intentó establecer un infructuoso proyecto de estudios folklóricos, que años más tarde fuera concretado gracias a sus vínculos con Ernesto E. Padilla (quien se desempeñaba, entonces, como gobernador de Tucumán). Rojas, quien en los años veinte era un actor central en el ámbito académico (ex decano y luego rector de la Universidad de Buenos Aires), sostenía, en cambio, que el acervo cultural argentino se encontraba integrado por un componente español y uno indígena, idea con la que Carrizo no coincidía, ya que este consideraba que la presencia del sustrato indígena era completamente secundaria. En contraste con la propuesta de Rojas, Carrizo plantea:

Por eso, porque España se vino de mudada, es que resulta difícil encontrar el alma indígena de América, a los que la creen india. Su suelo, su clima, sus lenguas aborígenes, su fauna, su flora, todo se podrá estudiar con prescindencia absoluta de España; pero el alma de América, nunca. Al contrario, cuanto más conozcamos la España medioeval y renacentista, más conoceremos a América. [...] Día llegará en que, mejor informados nuestros escritores de la cultura hispánica, se convencerán de que nuestro indianismo desaparece a medida que se conoce mejor el acervo espiritual del pueblo español de la conquista. (1937, pp. 183-184. El resaltado es nuestro)

Aun cuando "el indio que le interesaba rescatar [a Rojas] era una referencia espiritual que llegaba del pasado, antes que una presencia concreta actual" (Adamovsky, 2016, p. 3), es evidente la diferencia con el planteo de Carrizo. Las siguientes palabras Rojas así lo demuestran:

En lo que respecta a las razas indígenas, ese extravio nos llevó a un doble error: el primero fue considerar al indio civilizador de la conquista igual en salvajez y rebeldía a su sobreviviente refugiado en el Chaco; el segundo fue persuadirse a que el espíritu de nuestra subconciencia indígena hubiera desaparecido del país, porque ahora fuese nuestra religión el cristianismo, nuestro gobierno la democracia, nuestro idioma el castellano. Pero un estudio más completo de la génesis patria comienza a rehabilitar al indígena que el europeísmo proscribiera de la historia, como rehabilitará al español que fue proscrito a su turno por la pasión revolucionaria. (1940 [1912], pp. 96-97. El resaltado es nuestro)

Según Chamosa (2012), frente al rechazo de Rojas, Carrizo buscó en los fundadores de la Universidad de Tucumán y la élite azucarera de la región el aval para llevar adelante su proyecto de estudio del acervo cultural local. Esto, por otra parte, favorecería los intereses económicos y políticos de los señores azucareros, quienes buscaban demostrar la "europeidad" (en términos fenotípicos, la "blancura") de los tucumanos con el objetivo de revalorizar el comercio local y así insertar la producción azucarera de la provincia en el ámbito nacional. En el siguiente fragmento del Cancionero popular de Tucumán (1939), puede verse una operación mediante la cual Carrizo exalta la riqueza y potencial de la provincia, como así también su población a la que caracteriza mayormente "blanca":

El crecimiento asombroso que ha tenido [Tucumán] se debe principalmente a la riqueza de su suelo y a la industria azucarera, a que está consagrada la mayoría de su población.

Casi todos los habitantes son de raza blanca; hay escaso número de mestizos; tipos racialmente autóctonos no he visto, y ninguna estadística los menta. [...]

La población tucumana es estable porque su suelo rico, tiene suficientes fuentes de recursos y no se ve obligada a emigrar, como ocurre en Catamarca, La Rioja y Santiago del Estero, en donde el suelo árido no ofrece suficientes medios de subsistencia. Es debido a esta circunstancia que Tucumán es un centro tradicional importante, y lo ha de ser por muchos años, porque el tucumano se enorgullece de su pasado $y$, si en su suelo convive con el extranjero, no renuncia a sus tradiciones. (p. 11)

Pocos años después, en 1943, cuando Carrizo sea director del recientemente fundado Instituto Nacional de la Tradición, se registra el naciente interés del Estado por el 
estudio antropológico de la cultura y, más particularmente, por el estudio del "indio argentino" (véase Lazzari, 2002). Sin embargo, más allá de esta integración de la cuestión indígena como una preocupación estatal, la postura de Carrizo en cuanto a la inclusión de la influencia indígena en el folklore nacional se mantiene inalterada por varios años. ${ }^{7}$

Dijimos que también en 1943 Imbelloni publica Concepto y praxis del folklore como ciencia, ${ }^{8}$ una obra en la que reúne distintas conferencias ${ }^{9}$ donde expone, como su título lo indica, un modelo para el estudio del folklore desde la perspectiva de la escuela histórico-cultural. Esta escuela, que seguía los principios de la teoría difusionista, proponía identificar coincidencias entre diferentes culturas (en algunos casos, también geográficamente distantes) a partir del análisis de datos extraídos por distintas disciplinas como la lingüística, la etnografía, la arqueología o la musicología. Este material era organizado en ciclos y círculos culturales (categorías básicas de esta escuela), mediante las que se delimitaba el área que abarcaba la expansión de una cultura (círculos culturales) y las características intrínsecas que la definen (ciclos culturales) (Boschín y Llamazares, 1986; Imbelloni, 1936a).

En coherencia con la mencionada escuela, en Concepto y praxis Imbelloni introduce la definición de "antropología cultural", cuyo objetivo sería "la reconstrucción de los patrimonios". Allí la define como una macro-disciplina que abarcaría, por un lado, las ciencias "ontológicas", que son las encargadas del procesamiento y organización de ese material, a saber, la culturología y la etnología. Por otro lado, la antropología cultural estaría integrada por las ciencias "fenomenológicas", encargadas de la recolección de los datos en terreno, entre las cuales incluye a la prehistoria, la arqueología, la etnografía y el folklore, distinguidas por el objeto y el método de indagación. Las dos primeras se ocupan del estudio de las "civilizaciones desaparecidas"; la tercera, de la "civilización natural de pueblos [llamados] 'primitivos' y 'salvajes'" $y$, finalmente, el folklore se dedica a las "poblaciones que pertenecen a naciones civilizadas" (Imbelloni, 1943, p. 25). En este

\footnotetext{
${ }^{7}$ Así, en Historia del folklore argentino, publicado en 1953, admite el sustrato indígena como parte del patrimonio folklórico nacional: "Nos hemos acercado al indio en los siglos XVI, XVII, XVIII y aun en el XIX, porque entendemos que el estudiante de Folklore debe hacerlo aunque el etnógrafo le salga al paso, porque para los americanos es fundamental conocer las dos corrientes culturales que nos dieron el ser: la española y la indígena" (p. 11). Posiblemente este cambio de perspectiva se deba a su estrecha filiación con el peronismo, movimiento que, en ocasiones, buscó integrar elementos indígenas al patrimonio cultural nacional, como se verá más adelante.

${ }^{8}$ Poco más de quince años después, en 1959, esta obra pasa a integrar un libro en el que se compilan distintos trabajos de los principales referentes de los estudios del folklore (además de Imbelloni, participan Bruno Jacovella, Susana Chertudi, Augusto Cortazar, Felix Coluccio, Armando Vivante, Delia Millán de Palavecino, Enrique Palavecino y Ricardo Nardi), titulado Folklore argentino (Imbelloni, 1959).

9 Estas conferencias fueron pronunciadas en el Departamento de FoIklore del Instituto de Cooperación Universitaria, dirigido precisamente por Carrizo. Para más información sobre esta institución, véase Bentivegna (2016).
}

esquema, los pueblos indígenas no son incluidos dentro de los estudios folklóricos. Sin embargo, más adelante, al momento de definir las características específicas del folklore de las naciones americanas, adapta el marco teórico a las realidades locales. En este sentido, plantea:

Resumiendo: no será suficiente conocer los patrimonios antiguos y actuales de las naciones europeas (y sus grupos regionales) que dieron cuerpo a la Conquista y a las "grandes inmigraciones" de la segunda mitad del siglo XIX, sino hay que añadir otras dos componentes primarias, racialmente más alejadas: la negra y la india. (Imbelloni, 1943, p. 79. El resaltado es nuestro)

Entonces, la posibilidad de aceptar también elementos culturales de la población indígena en la conformación del patrimonio cultural argentino se debe, según el autor, a tres "modos de compenetración" (1943, p. 80): el primero que presenta es la lengua, "que nos pone frente a pueblos de variada mestización, con predominio creciente de blancos, los cuales se expresan en la vida cotidiana, y más en los cantares, con vocablos del Qhesua y algunos pocos del Cacán y del Guaraní" (1943, p. 80). El segundo consiste en una reformulación de la temporalidad en el relato histórico con la que logra superar la distinción anteriormente expuesta entre etnología y folklore, en sus palabras: "una nueva cronología, que veda colocar como base distintiva entre la Etnografía y el Folklore (esto es, entre los pueblos naturales y los civilizados) la fecha de la Conquista, porque con la fundación de los primeros núcleos de población coloniales no se interrumpió el flujo vital indio, y sólo se le atrajo dentro de los recintos (fortines, misiones, reducciones, aldeas)" (1943, p. 80). El tercero, finalmente, que refiere a fronteras territoriales, las cuales "no pueden coincidir con los confines de las naciones americanas actuales, por la simple razón que las influencias del Perú se extienden a Chile, Argentina, Bolivia y Ecuador, y la de los pueblos naturales de la Amazonia cubren casi todo el Brasil y el Paraguay, e importantes sectores de Bolivia, Argentina y Uruguay" (1943, p. 80).

En este sentido, más en la línea de Rojas que de Carrizo, Imbelloni, en un gesto relativamente marginal dentro de las tendencias del momento (y que se distingue de la $H N A$, donde localizaban las culturas indígenas en la prehistoria del país), desde el ámbito del folklore, considera que algunas marcas de esas culturas perviven como "sustrato" en el léxico y el arte verbal regional y las integra al patrimonio de las naciones americanas.

La asignación del elemento indígena a distintos momentos en sus obras de 1936 y 1943 se puede entender como una consecuencia propia de las distintas disciplinas en las que se inscriben estos trabajos. Así, la historia, reservada para el estudio del pasado nacional, no admite la inclusión de los pueblos indígenas en sus anales, temática abordada por la arqueología o, en todo caso, por la antropología. Por su parte, el folklore, si bien también supone el estudio 
de las manifestaciones culturales de la nación, se focaliza en la cultura popular, razón que permite explicar la incorporación del elemento indígena.

Resulta llamativo, sin embargo, el contraste de la posición de Imbelloni con la de Carrizo, quien, en el mismo año, también desde los estudios folklóricos, rechazaba de plano la incorporación de la cultura indígena en el folklore nacional, como expusimos anteriormente. Una posible explicación podría ser el lugar desde donde enunciaban sus planteos entonces. Es decir, en la etapa anterior al peronismo, los autores realizaban su práctica en contextos ideológicos diferentes (diferencia que pronto se borrará cuando ambos se identifiquen con el mismo proyecto, el del peronismo). Así, Carrizo, desde el "interior", se encontraba en la necesidad de demostrar, contra los pronósticos más extendidos, la "blancura" y, consecuentemente, el valor que tenían las provincias para la definición de la nación. Imbelloni, por su parte, se pronunciaba desde la academia porteña y su interés, en todo caso, era el de crear una carrera específica, la de Ciencias de América (que propone en Concepto y praxis), que condensara las distintas ramas de las ciencias antropológicas y disciplinas afines, sin que esto pusiera en riesgo su propia identidad ni posición.

\section{Antropología, lenguas indígenas y peronismo}

Con la emergencia del peronismo se acrecientan aún más los replanteos acerca de la definición del pueblo argentino. Historiadores y antropólogos han problematizado la emergencia de nuevas identidades nacionales al calor del movimiento peronista (Adamovsky, 2012; Grimson, 2016; Guber, 1999; Ratier, 1971). Entre ellas, destacamos la de los "cabecitas negras", definida por Alejandro Grimson (2016) como fundamentalmente indígena y del interior del país, donde aún no había penetrado de lleno la modernidad:

Con lo cual queda claramente enmarcado en las dicotomías argentinas de tradición y modernidad, civilización y barbarie, capital e interior, urbano y rural, culto e inculto. [...] De este modo, se construye un "otro" negro (en el sentido argentino de "no-blanco") que, evidentemente, resulta crucial para poder definir la propia identidad blanca, europeísta, urbana, educada y antiperonista. La presencia de los "cabecitas negras" en la capital hizo añicos el mito de la homogeneidad y singularidad argentina, al tiempo que produjo como reacción una visión racial de una clase media blanca durante la época peronista. (p. 39)

Ezequiel Adamovsky (2012), por su parte, expone las tensiones que se dieron entre el propio proyecto de Perón y las clases populares, lo que complejiza aún más el panorama. Según plantea el autor, si bien distintos grupos que habían sido usualmente postergados ("los negros", "los pobres", "los indios", en definitiva, la "cultura plebeya") encontraron en el movimiento peronista una posibilidad de autoreivindicación y una potenciación de su poder al superar la fragmentación y convertirse en un sujeto político unificado; esta oportunidad no coincidía en todo ni tuvo un genuino acompañamiento del propio Perón. De hecho, su "visión política era la de un nacionalismo corporativista: aspiraba a organizar a las personas en 'corporaciones' de acuerdo con sus intereses específicos" (Adamovsky, 2012, p. 180).

Frente a esta tensión, nos preguntamos cómo puede leerse esta suerte de reconocimiento de uno de los grupos históricamente más postergados, los pueblos indígenas, desde el ámbito de la ciencia que, al momento, jugó un rol relevante en el movimiento peronista. De hecho, al asumir Perón la presidencia se reorganizó el plantel académico: hubo despidos de docentes de larga trayectoria en las universidades nacionales, incorporación de nuevos miembros y reacomodamiento de los adherentes al movimiento que lideraba en posiciones de mayor poder (Buchbinder, 1997).

Imbelloni fue uno de los beneficiados. Si bien, como plantea Pablo Perazzi (2014), al momento ya ostentaba una posición de gran relevancia en el campo científico, en el año 1947 es nombrado director del Museo Etnográfico de la Universidad de Buenos Aires, en reemplazo de Romualdo Ardissone, y en 1950, recibe uno de los dos únicos cargos de dedicación exclusiva que se crean en la Facultad de Filosofía y Letras de la misma universidad.

Desde la dirección del Museo Etnográfico, Imbelloni contribuye a la reorganización de los estudios antropológicos argentinos, específicamente mediante nuevas incorporaciones de personal en el Museo y la expansión de la escuela histórico-cultural como método y línea de investigación en la antropología local. Tan pronto como obtiene el nombramiento, crea el Instituto de Antropología, del cual pasará a depender el Museo, y ambos quedan bajo su dirección. Forma parte de su estrategia hacer coincidir el proyecto del Instituto con el plan nacional. Con la misma tónica, en el informe que eleva sobre su proyecto de gestión para el naciente Instituto, se propone:

[...] encarar desde ya un plan de trabajo a cumplirse año $a$ año durante el período que se abre ante nosotros, de manera que pueda en nuestra esfera complementar las intenciones generales el plan de gobierno nacional, y forme, por decir así, nuestro propio 'plan quinquenal'. (AGFFyL, C-7-15, 12. El resaltado es nuestro)

En este mismo sentido, sugiere articular la cultura "popular" con el conocimiento especializado:

Por una parte hay que felicitar a la Facultad y al Instituto por verse favorecidos con colecciones [de arqueología, etnografía y antropología del Museo Nacional de Ciencias Naturales] de tan incalculable valor, las cuales valdrán para 
condensar el patrimonio y llenar las salas del edificio del Museo Antropológico de la Facultad, convirtiéndolo en un centro de atracción y cultura popular y especializada. (AGFFyL, C-7-15, 11. El resaltado es nuestro)

De esta cita se destaca, precisamente, el adjetivo "popular", novedoso dentro de las ciencias antropológicas, usualmente acompañadas por adjetivos tales como "autóctono", "aborigen" o "indígena".

En este marco, nos interesa rescatar otro acontecimiento clave que nos permitirá dar cuenta de las tensiones y matices en cuanto a la consideración de los grupos indígenas durante el período. En el mes de agosto de 1949, el bloque peronista presenta un proyecto en el Senado de la Nación de creación de seis institutos de "lenguas autóctonas" en las distintas regiones del país, lo que va en consonancia con el primer plan quinquenal, que proponía el estudio de las lenguas indígenas "no sólo como reliquias de un pasado idiomático cuya influencia aún perdura sino también como elementos vivos de convivencia en las zonas originarias" (Plan de Gobierno 1947-1951: p. 2848). Si bien el proyecto en cuestión nunca fue concretado, es relevante destacar los objetivos que perseguía:

Artículo 1 - Créase, dependiente de la Universidad Nacional y con un régimen de autonomía interna compatible con las prescripciones de la ley 13-301 y el decreto del Poder Ejecutivo de la Nación 9.956 del 7/IV/48, una organización destinada al estudio de las lenguas que fueron habladas en el territorio nacional por los pueblos autóctonos, con el fin de analizar, comparar y registrar los elementos idiomáticos de los mismos, los cuales deben servir en particular modo para la reconstrucción del panorama lingüístico aborigen de dicho territorio en su aspecto glotológico, etnográfico, e histórico, en calidad de contribución argentina a esa rama de las Ciencias del Hombre, sin descuidar-como necesario complemento-, los aportes que aquellos materiales brindaron al habla del pueblo argentino y las variaciones, enriquecimiento y otras modificaciones que desde los tiempos de la conquista hasta hoy han sufrido las lenguas autóctonas que se han conservado en uso en determinados sectores de la Mesopotamia, el Noroeste argentino, la Pampa y los territorios del Sud. (DCSN, 1949, p. 1355)

En resumidas cuentas, esta propuesta tenía como principal objetivo estudiar las lenguas indígenas del país por su valor como conocimiento para la humanidad, como también por su influencia en las distintas variedades del castellano hablado en Argentina. Como puede verse en la última parte de la cita, además, Imbelloni refiere a lenguas en uso, sin alusiones a su extinción futura, como se venía sosteniendo hasta entonces.

Imbelloni tuvo una participación de relevancia en la elaboración de este proyecto, ya que fue consultado por los legisladores en tanto especialista. Su postura, sin embargo, no fue precisamente favorable. Si bien en el informe que presenta reconoce el fundamento patriótico sobre el que se erige el proyecto, además de representar "una cálida comprensión de las finalidades generales del Gobierno del Gral. Perón con respecto a la revivificación de las tradiciones nacionales" (AME, Fondo de gestión José Imbelloni), inmediatamente añade:

Tampoco en el aprendizaje de las lenguas autóctonas pueden tenerse por mira objetivos prácticos, y el que principalmente propone el autor diciendo que las lenguas autóctonas sirven para explicarnos las peculiares locuciones de determinados ámbitos de la República (los provincialismos) es del todo desproporcionado al sacrificio pecunario que importa la organización que tal enseñanza requiere. (AME, Fondo de gestión José Imbelloni)

Es decir, para Imbelloni, el sustrato indígena en las variedades dialectales locales no era lo suficientemente significativo como el gasto que implicaría la creación de instituciones dedicadas específicamente al estudio de estas lenguas. Luego de dar su veredicto, plantea que lo ideal sería, entonces, en lugar de organizar estos institutos, crear la mencionada carrera de Ciencias de América, un proyecto que ya había planteado en Concepto y praxis, libro al que remite en este informe.

En algunas partes de su informe se reconoce la vitalidad de estas lenguas $y$, si bien plantea que aún es posible contactar a sus hablantes (de hecho, en el marco de su dirección del Museo Etnográfico, él mismo se encargará, meses después del debate de este proyecto, de registrar algunos vocablos de la lengua tehuelche, durante una expedición a Santa Cruz [Domínguez, 2017]), estos son demasiado escasos, de modo que no vale la pena (ni la erogación) organizar los mencionados institutos. Es decir, la "poca" vitalidad de las lenguas indígenas que él diagnostica, más su caracterización como "lenguas de cultura" (i. e., de una cultura singular) en contraposición a los "idiomas modernos", lo llevan a hacer una contrapropuesta que, en definitiva, mantiene a las lenguas y culturas indígenas como parte del pasado. Así, para Imbelloni el estudio de las lenguas indígenas no tiene un valor en sí, sino sólo en función de la comprensión de la difusión de las culturas.

Sin embargo, también en 1949, en una conferencia dictada en el marco de un ciclo organizado por el Ministerio de Cultura de la Nación, puede reconocerse una postura matizada de parte de Imbelloni en cuanto a la vitalidad de los grupos indígenas:

[...] la Antropología está muy lejos de ser una ciencia cadavérica, ya que es viva y actual, y que si las calaveras y fósiles caen, también ellos, bajo su régimen, sus materiales más abundantes y provechosos son los seres humanos que respiran, los pueblos y razas que llenan la superficie del planeta con sus obras y afanes. Ya que el 
fin de la antropología es el análisis de ambas formas de la vida del hombre: la orgánica y la cultural. (Imbelloni, 1949, p. 198)

Un año después, participa en una publicación impulsada por el peronismo que pone en escena nuevamente esta temática: la cuarta reedición de la Toponimia patagónica de etimología araucana de Perón (1950), reedición que esta vez estuvo a cargo de la Dirección General de Cultura del Ministerio de Educación de la Nación. Se trata de una edición más lujosa que las anteriores, ${ }^{10}$ que además cuenta con un prólogo de Imbelloni: "El panorama lingüístico de la Patagonia y el trabajo del General Perón".

En esa introducción, el antropólogo propone una historización del pueblo mapuche y de su enfrentamiento con el grupo tehuelche, caracterizados, estos últimos, como víctimas de aquellos, cuya supervivencia fue posible gracias a "las rápidas y resolutivas acciones finales del General Villegas (1883)", quien logró que "una escasa porción nativa [de la Patagonia] haya conservado su idioma hasta nuestros días" (Imbelloni, 1950, p. IX). Más allá de esta última referencia, lo cierto es que Imbelloni otra vez silenciará la actualidad de las lenguas indígenas y remitirá, nuevamente, a estos pueblos al ámbito de la arqueología:

La presente publicación, por su índole y finalidad, y por el mismo tono de su presentación tipográfica, que la Dirección General de Cultura ha cuidado en forma particular, no se dirige a los especialistas que dedican sus afanes cotidianos a desentrañar la construcción interior de las lenguas y su complicada historia espacial, sino -más en general- a todos los hombres cultos que hayan alimentado en mayor o menor grado la innata curiosidad por conocer a los pueblos que habitaron un día las distintas regiones del país y dejaron impresas en el paisaje y diseminadas en el suelo las improntas de sus industrias y costumbres. (Imbelloni, 1950, pp. VII-VIII. EI resaltado es nuestro)

En los casos en que refiere a las poblaciones actuales, aun cuando ha interactuado con hablantes de las lenguas, se mantiene en el tópico de su próxima desaparición:

Se trata de contactos sobrevivientes de la rama tehuelche del extremo austral, los aónikenk, que nos han sorprendido sobremanera por sus facultades idiomáticas excepcionales. Hemos averiguado personalmente que son bilingües, en su gran mayoría trilingües, pues hablan el castellano con bastante agilidad y propiedad, luego el aonico-aish que es su lengua materna, y el mapuche. Hemos conocido a varios que en materia de lenguas

\footnotetext{
${ }^{10}$ La primera edición fue publicada por el Ministerio de Agricultura entre 1935 y 1936; la segunda, de 1948, por la Biblioteca Nacional; la tercera, por la revista Archivos ethnos, también en 1950. Por su parte, la edición de 1950 de la Dirección General de Cultura de la Nación se destaca por tener en su haber dos ejemplares forrados en cuero con ilustraciones de temática ecuestre destinados a Perón y Evita. Los otros ejemplares también contienen estas imágenes, pero son de confección más austera.
}

nativas no poseían únicamente el aónico-aish, sino también la de sus consanguíneos e inmediatos vecinos del Norte, los guénena-kene, o tehuelche septentrionales. Estos guénena-kéne están actualmente en un grado más avanzado de extinción, y dentro de una decena de años no quedará el menor vestigio de su existencia. Su lengua fue el guénena-yajish, también -naturalmentedestinada a desaparecer en el labio de los vivientes (se están realizando registraciones y estudios con el fin de no perder del todo su material sonoro y léxico). (Imbelloni, 1950, p. IX)

En síntesis, resulta interesante retomar el fragmento citado anteriormente del Primer Plan Quinquenal (1947-1951, p. 2848) ya que cristaliza esta oscilación, característica del período. Así, por un lado, las lenguas indígenas eran organizadas junto con toda una serie de elementos simbólicos y materiales con los que se caracterizaba el pasado remoto y que, en tanto tales, debían ser registradas antes de su extinción definitiva. Sin embargo, se reconoce, acto seguido, que se mantiene como "elemento vivo" en las "zonas originarias". Imbelloni es partícipe de esta caracterización no como un simple reproductor, sino como uno de sus principales impulsores. Se debate, así, entre reconocer la evidente existencia de pueblos indígenas y su anclaje en un pasado cuya ubicación temporal vacilará de acuerdo con la coyuntura y la posición política o ideológica del autor.

\section{A modo de conclusión}

En esta ocasión nos propusimos abordar, a lo largo de un período particular del campo científico argentino, los distintos matices que recibió la problemática indígena en la construcción de narrativas históricas. Se tomó como punto de referencia el problema de las lenguas, ya que fue uno de los principales ejes sobre los que gravitó la disputa acerca de la ubicación temporal de estos pueblos en la historia, ya sea como parte del presente, ya como parte del pasado. Si a mediados de la década del treinta aún se reconoce una operación discursiva de ocultamiento como parte de la realidad contemporánea y un consecuente silenciamiento de sus lenguas, hacia comienzos de la década del cuarenta es posible identificar la incorporación de las lenguas y culturas indígenas en los debates acerca del "tipo argentino" que incluyen, en algunos casos, ciertos elementos indígenas como parte del patrimonio nacional y la penetración, en modo de sustrato, de sus lenguas en la lengua nacional. Este cambio puede explicarse gracias a la institucionalización del folklore, proceso que, a su vez, fue efecto de un cambio en la composición étnica de la población nacional y de la Segunda Guerra Mundial a nivel global. Finalmente, con la emergencia del peronismo, la problemática se complejiza aún más. Si bien a partir de entonces los pueblos indígenas comenzaron a integrar un nuevo sujeto político colectivo, la "cultura plebeya" (Adamovsky, 2012), el discurso científico, por su parte, no logró superar la idea de su inminente extinción ni el procedimiento discursivo 
de ubicarlos en un pasado lejano.

Buenos Aires, 25 de enero de 2018

\section{Agradecimiento}

La idea original de este trabajo fue gestada en el seminario de doctorado "Historias para la Argentina del siglo XX. La nación y sus pasados en el debate político y cultural (19101970)", dictado por Alejandro Cattaruzza, a quien agradezco su atenta lectura y sus sugerencias siempre pertinentes.

\section{Bibliografía}

Adamovsky, E. (2012). Historia de las clases populares en Argentina (1880-2003). Sudamericana: Buenos Aires.

Adamovsky, E. (2016). "Criollismo, política y etnicidad en la obra de Martín Castro, cantor anarquista (c. 1920-1950)". Quinto sol 20 (3). [Disponible en https://cerac.unlpam.edu.ar/ index.php/quintosol/article/view/895/1617; última consulta realizada: 11/06/2018.]

Archivo de la Facultad de Filosofía y Letras (= AGFFyL) de la Universidad de Buenos Aires. Cajas C-2-5 y C-7-15.

Archivo del Museo Etnográfico (= AME) de la Facultad de Filosofía y Letras de la Universidad de Buenos Aires. Fondo de gestión José Imbelloni.

Balandier, G. (1970). "El concepto de 'situación' colonial". Cuadernos del Seminario de Integración Social Guatemalteca. Ministerio de Educación de Guatemala.

Bentivegna, D. (2012). “El canto y la letra. Disputas en torno a la definición de lo tradicional en Juan A. Carrizo y Ricardo Rojas". Actas del V Congreso Internacional de Letras, 389-401. Editorial de la Facultad de Filosofía y Letras de la Universidad de Buenos Aires.

Bentivegna, D. (2016). "La Revista del Instituto Nacional de la Tradición: estudios folklóricos, nacionalismo y tradicionalismo en el primer peronismo". En Korn, G. y Panella, C., Ideas y debates para la nueva argentina, III, 107-134. La Plata, Universidad Nacional de La Plata.

Blache, M. (1991-1992). "Folklore y nacionalismo en la Argentina: su vinculación de origen y su desvinculación actual". Runa. Revista para las ciencias del hombre XX, 69-89.

Blache, M. y A. M. Dupey. (2007). "Itinerarios de los estudios folklóricos en la Argentina". Relaciones de la Sociedad Argentina de Antropología XXXII, 299-317.

Boivin, M.; Rosato, A. y Arribas, V. (Orgs.) (2016). Constructores de otredad. Antropofagia: Buenos Aires.

Boschin, M. T. y Llamazares, A. M. (1986). “La Escuela HistóricoCultural como factor retardario del desarrollo científico de la Arqueología argentina". Etnia 32, 101-156.

Buchbinder, P. (1997). Historia de la Facultad de Filosofía y Letras. Universidad de Buenos Aires. Buenos Aires: Eudeba.
Carrizo, J. A. (1937). Cancionero popular de La Rioja. Buenos Aires: A. Baiocco y cía editores.

Carrizo, J. A. (1945). Antecedentes medievales en la poesía tradicional de Argentina. Buenos Aires: Publicaciones de estudios hispánicos.

Carrizo, J. A. (1948). "La Revista del Instituto Nacional de la Tradición". Revista del Instituto Nacional de la Tradición 1 (1), 5-6.

Carrizo, J. A. (1953). Historia del folklore argentino. Buenos Aires: Instituto Nacional de la Tradición, Ministerio de Educación.

Cattaruzza, A. (2003). "La historia y la ambigua profesión del historiador en la Argentina de entreguerras". En Cattaruzza, A. y Eujanián, A. Políticas de la historia, Argentina 1860-1960, 103-142. Alianza Editorial: Madrid-Buenos Aires.

Cattaruzza, A. (2007). Los usos del pasado. La historia y la política argentinas en discusión, 1910-1945, Buenos Aires: Sudamericana.

Cattaruzza, A. (Coord.) (2001). Nueva Historia Argentina. Tomo VII. Crisis económica, avance del estado e incertidumbre política (1930-1940). Buenos Aires: Sudamericana.

Cattaruzza, A. (2016). Historia de la Argentina. 1916-1955. Buenos Aires: Siglo XXI.

Chamosa, O. (2012). Breve historia del folclore argentino (1920-1970). Identidad, política y nación. Buenos Aires: Edhasa. Chein, D. (2006). "Proceso de constitución del campo nacional de la folklorología: posicionamientos, articulación social y resignificación de la teoría". Silabario, n 9, 109-128.

De Jong, I. (2005). "Entre indios e inmigrantes: el pensamiento nacionalista y los precursores del folklore en la antropología argentina del cambio de siglo (XIX-XX)". Revista de Indias, LXV (234), 405-426.

Diario de la Cámara de Senadores de la Nación (= DCSN). 1949. Sesión del 26 de agosto de 1949, 41 reunión, 37 sesión ordinaria.

Domínguez, L. (2017). “Un vocabulario tehuelche en el olvido. La expedición liderada por José Imbelloni a la Patagonia argentina en el año 1949 y el registro de material lingüístico". Actas de las VIII Jornadas Internacionales de investigación en Filología y Lingüística y II en Crítica Genética "Las lenguas del archivo", del 21 al 23 de junio, Universidad Nacional de La Plata.

Domínguez, L. (2018). "Lenguas indígenas a comienzos del siglo XX en Argentina". Ponencia presentada en el XVI Congreso de la Sociedad Argentina de Estudios Lingüísticos, del 3 al 6 de julio de 2018, Universidad Nacional de San Martín.

Escudero, E. A. (2010). Ricardo Levene: políticas de la historia y de la cultura (1930-1945). Ferreyra editor: Córdoba.

Fígoli, L. (2004). “Origen y desarrollo de la antropología en la Argentina: de la Organización Nacional hasta mediados del siglo $X^{\prime \prime}$. Anuario de estudios en Antropología Social, Centro de Antropología Social - Instituto de Desarrollo Económico y Social (CAS-IDES), 71-80. 
García Fanlo, L. (2011). "La argentinidad: un marco interpretativo". Polis, Revista Latinoamericana 29, 1-17. [Disponible en https:// journals.openedition.org/polis/2053. Última consulta realizada: 11/06/2018.]

Gil, G. L. (2016). “Relatos antropológicos periféricos. Los autores argentinos en el Handbook of South American Indians". Memoria Americana. Cuadernos de Etnohistoria 24 (2), 19-37.

Glozman, M. (2010). "Políticas lingüísticas y representaciones de la nación. La cuestión de las lenguas indígenas en los planes gubernamentales del primer peronismo". Ponencia presentada en el III Congreso de laS lenguaS. Rosario, 22 al 25 de mayo de 2010.

Grimson, A. (2016). "Racialidad, etnicidad y clase en los orígenes del peronismo, Argentina 1945". desiguALdades.net, Working Paper Series 93, Berlín. [Disponible en http://www.iai. spk-berlin.de/fileadmin/dokumentenbibliothek/desigualdades/ workingpapers/93_WP_Grimson_Online.pdf. Última consulta realizada: 11/06/2018]

Guber, R. (1999). "'El Cabecita Negra' o las categorías de la investigación etnográfica en la Argentina". Revista de Investigaciones Folklóricas 14, 108-120.

Imbelloni, J. (1936a). Epítome de culturología. Buenos Aires: Nova.

Imbelloni, J. (1936b). "Lenguas indígenas del territorio argentino". En Levene, R., Historia de la Nación Argentina, 177-205. Buenos Aires: El Ateneo.

Imbelloni, J. (1943). Concepto y praxis del folklore como ciencia. Buenos Aires: Editorial Nova.

Imbelloni, J. (1949). "Antropología. Investigadores e investigaciones. Etapas de esta ciencia en nuestro país". Primer ciclo anual de conferencias 1 (III) (4), 194-215. Ministerio de Educación de la Nación.

Imbelloni, J. (1950). "El panorama lingüístico de la Patagonia y el trabajo del General Perón". En Perón, J. D., Toponimia patagónica de etimología araucana. Edición de la Dirección General de la Cultura del Ministerio de Educación de la Nación.

Imbelloni, J. (Comp.). (1959). Folklore argentino. Buenos Aires: Editorial Nova.

Lazzari, A. (2002). "Indio Argentino, Cultura (Nacional): del Instituto Nacional de la Tradición al Instituto Nacional de Antropología (1943-1976)". En Guber, R. y Visacovsky, S. (eds.), Historias y estilos etnográficos en la antropología argentina, 153-201. Buenos Aires: Editorial Antropofagia.

Lazzari, A. (2004). “Antropología en el Estado: el Instituto Étnico Nacional (1946-1955)". En Neiburg, F. y Plotkin, M. (eds.), Intelectuales y Expertos. La constitución del conocimiento social en la Argentina, 203-229. Buenos Aires: Paidós.

Levene, R. (Coord.). (1936). Historia de la Nación Argentina. Buenos Aires: El Ateneo.

Mandrini, R. (2003). "Hacer historia indígena. El desafío a los historiadores". En Mandrini, R. y Paz, C. (eds.), Las fronteras hispanocriollas del mundo indígena latinoamericano en los siglos XVIII-XIX Un estudio comparativo, 15-32. Tandil: IEHS/ CEHIR/UNS.

Outes, F. F. (1931). "La reorganización del Museo Antropológico y Etnográfico de la Facultad de Filosofía y Letras". Solar, 13-39.

Outes, F. F. (1937). “Crónica oficial". Relaciones 1, 196-204.

Montani, R. 2016. "Lengua y artefactos en la etnografía wichí de Alfred Métraux". Journal de la Société des Américanistes $102,75-97$

Perazzi, P. (2014). “Peronismo, posperonismo y profesionalización: trayectorias académicas, estrategias de autopreservación y círculos discipulares en la antropología porteña, 1945-1963". Sociohistórica 34, 1-11.

Perón, J. D. (1950). Toponimia patagónica de etimología araucana. Edición de la Dirección General de la Cultura del Ministerio de Educación de la Nación.

Piazzini Suárez, C. E. (2006). “Arqueología, espacio y tiempo: una mirada desde Latinoamérica". Arqueología suramericana 2 (1), 3-25.

Perilli de Colombres Garmendia, E. (2006). "Alfred Métraux y la Universidad Nacional de Tucumán". Actas del Primer Congreso sobre la Historia de la Universidad de Tucumán: 143-153. Tucumán: Secretaría General, UNT.

Podestá, M. M. (2007). "70 años en la vida de la Sociedad Argentina de Antropología". Relaciones de la Sociedad Argentina de Antropología XXXII, 9-32.

Podgorny, I. (2001). "La clasificación de los restos arqueológicos en la Argentina, 1880 1940. Primera parte: La diversidad cultural y el problema de la antigüedad del hombre en el Plata. Saber $y$ tiempo 12, 5-26.

Podgorny, I. (2002). "La clasificación de los restos arqueológicos en la Argentina, 1880-1940. Segunda parte: Algunos hitos de las décadas de 1920 y 1930". Saber y tiempo 13, 5-31.

Podgorny, I. (2004). "'Tocar para creer'. La arqueología en la Argentina, 1910-1940". Anales del Museo de América 12, 147-182.

Plan de Gobierno. (1947-1951), “Exposición del Plan de Gobierno (1947-1951) hecha por el Excelentísimo Señor Presidente de la Nación, General de Brigada Don Juan Perón, en la Reunión Conjunta de octubre de 1946", 2847-2850. Buenos Aires: Presidencia de la Nación/Secretaría Técnica.

Ratier, H. (1971). El cabecita negra. Buenos Aires: Centro Editor de América Latina.

Rojas, R. (1940 [1912]). Blasón de plata. Buenos Aires: Losada.

Vega, Carlos. (2016 [1946]). Los instrumentos musicales aborígenes y criollos de la Argentina. Buenos Aires: Educa.

Villalón, A. (2012). "Políticas inmigratorias en la Argentina de los '40". Publicar. En antropología y ciencias sociales, 31-50. 